\title{
The Role of Culture and Religion on Conception and Regulation of Visual Privacy
}

\author{
Zaiton Abdul Rahim \\ International Islamic University Malaysia, Malaysia \\ zaiton@iium.edu.my
}

\begin{abstract}
This paper examines the role of culture and religion in the conception and regulation of visual privacy and design attributes affecting it. The study involves a survey interview of 381 respondents and 11 case studies of Malay Muslims living in two-storey terrace housing in urban areas in Malaysia. Findings indicate despite changes in living condition and a new paradigm in culture-housing, culture and religion play an important role in the conception and regulation of visual privacy. Successful regulation through the physical element and behavioural norms provides visual privacy despite the lack of visual privacy due to design attributes.

Keywords: Visual privacy; culture; religion; privacy regulation

eISSN 2398-4295 @ 2018. The Authors. Published for AMER ABRA cE-Bs by e-International Publishing House, Ltd., UK. This is an open-access article under the CC BY-NC-ND license (http://creativecommons.org/licenses/bync-nd/4.0/). Peer-review under responsibility of AMER (Association of Malaysian Environment-Behaviour Researchers), ABRA (Association of Behavioural Researchers on Asians) and CE-Bs (Centre for EnvironmentBehaviour Studies), Faculty of Architecture, Planning \& Surveying, Universiti Teknologi MARA, Malaysia.

http://dx.doi.org/10.21834/ajbes.v3i11.112
\end{abstract}




\subsection{Introduction}

Some authors are in the opinion that privacy was given low priority in the traditional Malay society; a contradiction to Islam that put stressed the importance of privacy for he family. This opinion can be argued as privacy is culturally specific (Altman, 1977; Newell, 1994 and Fahey, 1995) and therefore should be perceived from the perspective of the culture in question. Privacy in different cultures was translated into different physical levels and responses in the design of houses. Westin (1967) argues that privacy operated at the individual, group, and organizational/institutional levels but stressed that his theory of privacy is applicable specifically to Western cultures because it is consistent with the socio-political values of Western democracies. Privacy is one of the outstanding ways in which cultures differ, resulting in different house forms around the world (Rapoport, 1969). The house is the primary setting for privacy design attributes of the house act as important privacy regulating mechanisms in providing a comfortable level of privacy. Architectural and behavioural variables operate in tandem to control privacy in the built environment to satisfy psychological needs (Altman, 1977).

In Islam, the architectural, social, and psychological dimensions of privacy are fundamental to the daily life of the Muslims. Visual privacy is one of the most important aspects of privacy in the design of houses. A house should provide visual insulation from outside; allows control of visual exposure and freedom from visual access. Visual exposure where the probability that one's self and behaviour is seen by sight from one's immediate surroundings is prohibited. Visual privacy influenced the specifics of doors, windows and openings, space organisation, the position of the house and physical elements such as partitions, walls, blinds, louvres, landscape and architectural design strategies.

Extant literature has indicated the link and relationship between behaviour and environment (Wapner, Demick, Yamamoto \& Minami, 2000). Privacy is a process which involved a continuous regulation of privacy through behavioural and environmental mechanisms. An appropriate physical setting and behaviour influence the definition of privacy and environmental quality as the built environment is a determinant of behaviour and behavioural adaptation is a spontaneous response to constraints in the environment (Archea, 1977). Altman (1977) posited that the environment is both "a determinant of behaviour and as an extension of behaviour". Successful privacy regulation provides a comfortable level of visual privacy. The built environment and social behaviour, of which privacy is part of, are interdependent. Changes in one aspect will have a direct influence on the other. The lack of consideration for privacy in the house design and its attributes may result in less than comfortable level of privacy. However, successful regulation of privacy through both behavioural and environmental mechanisms may provide a comfortable level of privacy.

\subsection{Literature Review}

Privacy should not be seen as an end in itself but a process of regulation that changed according to the need and setting. It is a dialectical process involving the individual's ability to control the permeability of interpersonal boundaries (Altman, 1977). Altman also posited 
two types of privacy regulating mechanisms; behavioural and environmental. Behavioural mechanisms include verbal and non-verbal behaviour and are influenced by socio-cultural factors. People in all cultures engaged in the regulation of social relationship and behavioural mechanisms by which accessibility is controlled and are probably unique to a particular physical, a psychological and social circumstance of culture. Successful regulation of privacy is essential in the process of achieving privacy when the physical environment lacks in privacy.

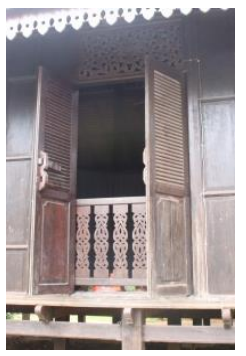

a. High window with decorative panels

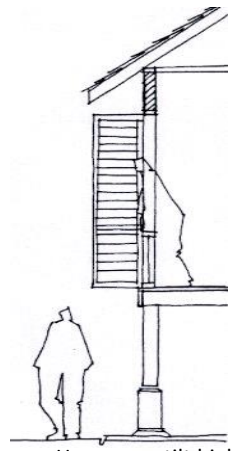

c. House on stilt higher than ground level

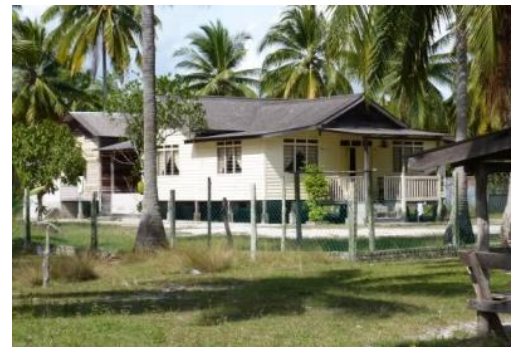

b. A Malay house within its context

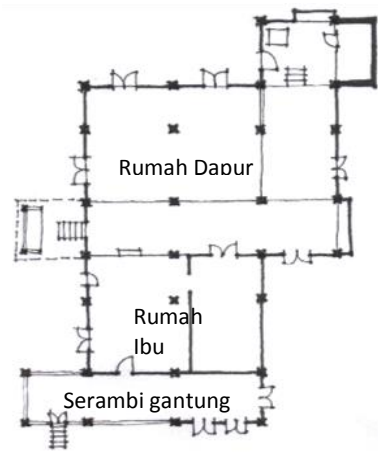

d. Layout of a typical traditional Malay house with clear division of domains

Figure 1 The traditional Malay house

Translation of privacy into the Muslims' houses varies between the cultures partly because Islam did not attempt to undo the local culture that embraced it particularly the one that does not deviate from its principles. The translation of visual privacy in Muslim houses reflects the need to balance between privacy and other factors such as geography, climate and the local culture. At times, the strong influence of the culture of origin precedes Islamic principles. Privacy appears to be given low priority in the traditional Malay culture partly from the openness of the traditional Malay house which appears to be lacking in privacy. This opinion is true if privacy is perceived from the Western perspective which emphasizes on 
individualism. Privacy in the close-knit Malay society is related to the community, and individualism was not emphasised. The idea of privacy in the traditional Malay society was based on gender roles, the position of women and separation of genders. The ability to create physical boundaries that exclude others hardly defines privacy in the traditional Malay society where behavioural norms were important privacy regulating mechanism. Privacy in the Malay society existed with different boundary, coverage and realisation.

Privacy in the traditional Malay house was achieved through the indigenous ways which responded to climate, geography and culture of the people; i.e. the positioning of the house on stilt higher from the ground level, high windows with decorative panels, careful location of doors or internal openings indirectly to each other and arrangement of spaces according to public and private domains (Figure 1). Physical elements such as curtain, screen and partition were used to provide visual privacy in the house. Spaces in the traditional Malay house are interchangeable and used for different activities.

The Malay custom, values, tradition and etiquette, governed the behavioural norm and regulated privacy. An individual should display proper behaviour both in the house and in public. Among the expected behaviour about privacy are not prying into the private matters of others, not looking into other people's houses, give salutation and enter the house only after given permission. Religious beliefs cultural norms, the way of life, social interaction and behavioural norms of the Malays remain to be important aspects in regulating privacy in the family (Noorul Huda \& Anuar, 2013). Zainal (1995) noted that the behavioural norms in Malay society are consistent with morality in Islamic teachings and to this extent, the Malay customs and Islam are in complete agreement. The observation of proper behaviour was important privacy regulating mechanism as compared to physical barriers.

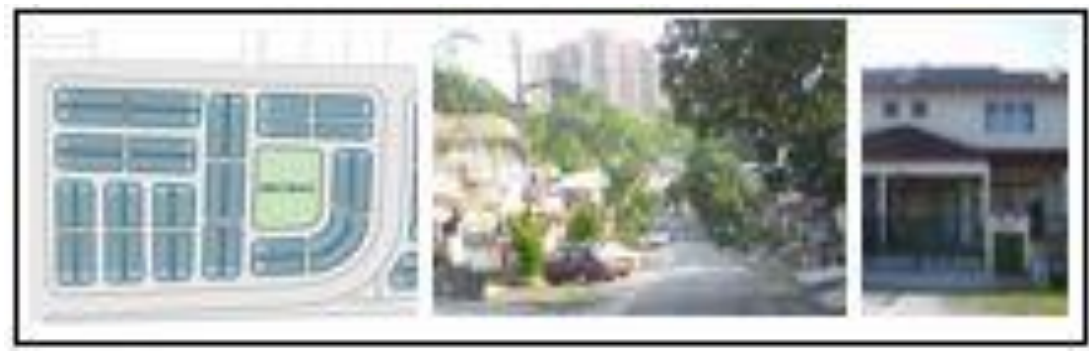

Figure 2 A typical terrace

Urban migration in Malaysia among the Malays in the 1970s indirectly changed their lifestyle and living environment. Most lived in the terrace housing (Figure 2), introduced by the British. The originality of terrace housing in its purpose and adoption, from the age of colonialism to its continuing implementation in modern Malaysia remained to be questionable (Salehaton, Erdayu, Hazlina \& Anniz Fazli, 2009). Finding by Ahmad Hariza, Zaiton, Syarifah Nurazizan and Nurizan (2006) indicated the contradiction between cultures and built environment have affected some aspect of the Malay culture. Zaiton and Ahmad Hariza 
(2012) found the lack of social and cultural consideration regarding privacy, activity system and social interaction resulted in the behavioural adaptation of the Malays at least until housing modification. Finding by Erdayu, Esmawee \& Masran (2009) indicated territorial expression through personalisation of terrace housing modification not only express the occupants' self-identity or image but also improved privacy and security. The addition of bedrooms in terrace houses was found to improve the privacy of the family (Erdayu, Esmawee \& Masran2010). Modification of terrace houses became a Malaysian culture and a manifestation of the inconsistency between housing design and culture. Ahmad Hariza et. al (2006) suggested changes in some aspect of the Malay culture during the process of adaptation due to the inconsistency between low-cost housing design and culture.

Changes in the built environment influenced changes in culture. The conception of visual privacy and regulation are expected to change over time due to a change in the way of life and the physical living environment. The changes may not be consistent with the Malay culture and Islam as an accepted way of life. Constraints imposed by the physical housing environment may cause psychological stress and impinge on one's felt sense of privacy due to the behavioural adaptations that they necessitate, affecting all of those living in it. Based on the discussion presented, the objectives of the paper are:

- To examine the role of culture and religion in the conception of visual privacy among the Malays

- To examine regulation of visual privacy in terrace houses

- To identify terrace housing design attributes influencing visual privacy

Changes in the built environment influenced changes in culture. The conception of visual privacy and regulation are expected to change over time due to a change in the way of life and the physical living environment. The changes may not be consistent with the Malay culture and Islam as an accepted way of life. Constraints imposed by the physical housing environment may cause psychological stress and impinge on one's felt sense of privacy due to the behavioural adaptations that they necessitate, affecting all of those living in it. Based on the discussion presented, the aim of this paper is to examine issues related to visual privacy of the Malay Muslim families in the context of terrace housing in the urban areas, in Malaysia. Specifically the objectives are:

- To examine the role of culture and religion on the conception on visual privacy among the Malays

- To examine regulation of visual privacy in terrace houses

- To identify terrace housing design attributes influencing visual privacy

\subsection{Methodology}

The study employs survey interview of 381 respondents and 11 case studies of Malay families living in two-storey terrace houses in two locations in the urban area of Klang Valley. The case studies were identified during survey interview phase based on the willingness of the respondents to be interviewed. Both quantitative and qualitative methods were used to provide more insight and depth into the issues of visual privacy in housing. The logic of the 
case study is to demonstrate a causal argument about how general social forces shape and produce results in particular settings.

The selection of respondents for case studies was based on their background gathered during survey interviews namely, family size, gender and age of children, family life cycle and housing design that may influence the conception of privacy at home. It is their relevance to the research topic rather than their representativeness, which determines the ways in which the people to be studied are selected in qualitative research (Flick, 1998). This study uses the second rule proposed by Lonner and Berry (1986), whereby one does the best one can under the circumstances to the appropriate sample, which permits the proper execution of the research.

\subsection{Results and Discussions}

Visual privacy in the study is measured based on a total of 6 items validated with a Cronbach alpha coefficient of 0.727 . Finding indicates visual privacy is needed for three main reasons; to allow for freedom in clothing $(78.0 \%)$, freedom in activities $(74.2 \%)$ and control of information in the house $(77.6 \%)$, consistent with the review of the literature. The notion of visual privacy as control of visual exposure and freedom from visual access correspond to the idea of shame and modesty, discomfort and embarrassment in the Malay culture and Islam. However, findings indicate that the conception of visual privacy may not be consistent to Islamic principle but influenced by Malay culture. Modesty in the context of visual privacy in the Malay culture is strongly related to the idea of clothing seen either from the perspective of Islam or Malay culture. Inappropriate clothing to respondents who observe Islam implies clothing that did not properly cover oneself according to Islam when public observation is effective, regardless of whether one is inside or outside the house. The same term implies that one is in clothing that is not acceptable to be seen by others at the public level or something is worn only in the house from the perspective of the Malay culture.

Finding indicates that the majority of the respondents $(89.6 \%)$ feel that the control of visual exposure is important. Control of visual exposure is associated with the freedom of action, behavioural pattern and activity system for normal functioning of daily activities and to conceal information that indirectly communicates the values and beliefs of the family to others. The idea of shame is not only applicable to how one should wear when seen by others but also how one sits, sleeps, eat and other acts. Control of visual exposure provides the family with the freedom to act and behave spontaneously without worrying their acts and behaviour are being observed by others. It is also important to control visual exposure within the private realm of the house in the presence of guests; i.e. the physical condition of the. Findings indicate that visual exposure from a car passing in front of the terrace houses is a concern to those who adhere to Islamic observance on covering their aurat (the part of the body not be seen by others). The case studies indicate that visual privacy is particularly important to those who follow strict observance of Islam as a way of life. Background of respondents 


\section{Regulation of visual privacy}

Findings indicate that both physical elements and behavioural norm are important privacy regulating mechanisms. Curtains, screens and blinds are the most important regulating mechanisms for visual privacy identified by $89.5 \%$ of the respondents as compared to the window $(65.1 \%)$ and the main door $(58.7 \%)$. There is no significance difference between genders, age, education or family income in the use of physical mechanisms in regulating visual privacy. Case studies indicate that windows and doors were left partially opened to balance the need for visual privacy and thermal comfort. Respondents who conceptualised visual privacy according to Islam are more likely to regulate visual privacy by closing the windows and doors. Curtain was found to be an important physical mechanism in providing visual privacy as it allows the family to see out without being seen.

Behavioural norm and expectation of specific behavioural norm from others provide visual privacy to the family consistent with the traditional Malay culture and Islam. Proper behaviour such as not looking into one's house, appropriate clothing, and limiting visual exposure in the presence of male guests and consideration for preservation of others' privacy of others within the neighbourhood were observed. The act of not looking into other houses appears to be more important in terrace housing to ensure privacy to the family and neighbours.

\section{Terrace housing design attributes influencing visual privacy}

The characteristic, location and position of windows and doors can hinder or promote privacy (Besim, 1986). Respondents living in terrace houses located directly facing each other are more likely to indicate the position of the main door affects their visual privacy as compared to those living in units facing open space, road, playground, etc. The translucent louvre window commonly used in the kitchen, bedrooms and bathrooms in terrace houses are preferred as it provides good ventilation and can be adjusted to control the view. The position of the kitchen door directly facing the neighbour's kitchen door is found to affect the visual privacy of the family as it allows a direct view of the house. The door is usually left opened or partially opened only during cooking. Despite its characteristics, the position and location of windows and doors are not seen as a major hindrance of visual privacy as these elements can be regulated. However, the lack of external wall or physical barriers dividing the external area of the houses gives rise to potential overlooking into the neighbour's houses and therefore affecting visual privacy.

Privacy in the house cannot be seen in isolation of the terrace housing environment. A literature review has shown that the proximity of terrace houses, position of windows and doors, walls and external elements such as road, trees and hedges influenced the privacy of individual families. Finding indicates the location and position of terrace houses external elements contributed to the satisfaction and perception on privacy achieved. Respondents whose terrace houses are located higher than their neighbours' houses, face an open space such as the green area, a road or a playground achieved a higher level of visual privacy as compared to their neighbours living in houses facing other terrace houses. 


\subsection{Conclusion}

The conception of visual privacy among the Malays is influenced the acceptance and practice of Islam as a way of life, an indication that the culture of origin is still dominant and overrules some aspects of religion in defining visual privacy and its regulation. The different perception on what is 'appropriate clothing' which is related to the need for freedom of visual access, suggested the complexity of visual privacy as a concept due to its cultural influences. Behavioural norms are found to be important regulation mechanisms among the Malay Muslim families and are consistent with the traditional Malay culture and Islam. Successful regulation of visual privacy through behavioural norms and physical elements provided the required visual privacy despite the lack of consideration for visual privacy in the terrace house design.

\section{Acknowledgement}

This study was part of a study on a grant by International Islamic University Malaysia.

\section{References}

Ahmad Hariza, H., Zaiton, A. R., Sharifah Norazizan, S. A. R. \& Nurizan, Y. (2006). Visual Privacy and Family Intimacy: A Case Study of Malay Inhabitant Living in Two-Storey Low Cost Housing. Journal of Environment and Planning $B, 33,301-318$.

Altman, I. (1977). Privacy Regulation: Culturally Universal or Culturally Specific? Journal of Social Issues, 33, 6684.

Azhan, A. A. \& Abdullah, S. A. (2012). Home Making in Low-Cost Housing Area. Procedia - Social and Behavioral Sciences, 49, $268-281$.

Besim, S. H. (1986). Arabic-Islamic Cities: Building and Planning Principles. New York: KPI Limited.

Erdayu, O. O., Esmawee, E. \& Masran, S (2009). Personalisation of the Home. Procedia - Social and Behavioral Sciences, 49, $328-340$.

Erdayu, O. O., Esmawee, E. \& Masran, S (2010). Not Your Perfect Home? How Malaysian Homeowners Make It Works. Procedia - Social and Behavioral Sciences, 42, 350 - 361.

Fahey, T. (1995). Family and Privacy: Conceptual and empirical reflections. Sociology: Journal of the British Sociological Association, 29(4), 687.

Flick, U. (1998). An Introduction to Qualitative Research. Thousand Oaks, California: Sage.

Lonner, W. J. \& Berry, L. W. (1986). Field Methods in Cross-cultural Research. California: Sage.

Newell, P. B. (1994). A System Models of Privacy. Journal of Environmental Psychology, 14 (1), 65-78.

Noorul Huda, M. R \& Anuar, T. (2013). The Concept of Privacy and the Malay Dwelling Interior Space Planning. Procedia - Social and Behavioral Sciences, 101, $404-414$. 
Salehaton, H. S., Erdayu, O. O., Hazlina, H. \& Anniz Fazli, I.B. (2009). Personalisation of Terraced Houses in Section 7, Shah Alam, Selangor. Procedia - Social and Behavioral Sciences, 49, 319 - 327

Wapner, S., Demick, J., Yamamoto, T., \& Minami, H. (Eds). (2000). Theoretical Perspectives in EnvironmentBehavior Research: Underlying Assumptions, Research Problems, and Methodology. New York: Kluwer Academic/Plenum Publishers.

Westin, A. F. (1967). Privacy and Freedom. New York: Atheneum.

Zainal, K. (1995). The Malay Family: Beliefs and Realities. Journal of Comparative Family Studies, 26, 43-60. 